\title{
A Workplace Curriculum and Strategies to Enhance Learning Experiences for Machining Workers
}

\author{
Azmir Mohd Yunus (Corresponding author) \\ Faculty of Educational Studies, Universiti Putra Malaysia \\ E-mail: azmiryunus@ @otmail.com
}

Ab. Rahim Bakar
Faculty of Educational Studies, Universiti Putra Malaysia

Azimi Hamzah

Faculty of Educational Studies, Universiti Putra Malaysia

Wan Marzuki Wan Jaafar

Faculty of Educational Studies, Universiti Putra Malaysia

Received: November 03, 2016 Accepted: December 08, 2016 Published: December 27, 2016 doi:10.5296/ijld.v6i4.10262URL: http://dx.doi.org/10.5296/ ijld.v6i4.10262

\begin{abstract}
Existing literature seldom discusses curricula and strategies used by employers to train workers who lack initial training for the occupations in which they are employed. This paper aims to add to this discussion within the context of skill formation for machining workers. The site of the study was a car engine factory in Malaysia. Using a qualitative case study methodology, data were obtained through interviews with the factory manager and trainers, observation of the factory and its training facility, and documents relating to training. The findings show that skill formation is planned as a gradual process. A gradual progression pathway was put in place to serve as both a career track and a learning track for workers. In order to enhance workers' learning experiences, the factory ensures that (1) workers have sufficient mathematical skill, (2) syllabus and training modules are used for training, (3) training is designed to maximize opportunities for practice, and (4) workers' skills are continuously assessed.
\end{abstract}

Keywords: Skill formation, Workplace curriculum, Training strategies, Machining workers 


\section{Introduction}

Skill formation in the workplace is a common phenomenon for many workers in Malaysia. According to the Department of Statistics (2013), 56\% of the Malaysian workforce has only secondary-level education; another $16.6 \%$ has only primary education and $2.9 \%$ have no formal education at all. In the manufacturing industry, people with secondary and lesser qualifications form $80.8 \%$ of the labor force in manufacturing, or roughly 1.6 million workers (Department of Statistics 2012, p. 15). For those who begin employment without relevant qualifications and experience, skill formation is likely to happen at work. However, despite the apparent pervasiveness of skill formation in the workplace, especially among those who lack formal education, the systems and strategies to support it are seldom discussed.

In this paper, the authors examine how an employer trains workers with skills in machining technology. Machining is a process in which machine tools are used to cut metals into precise shapes. The term 'machine tools' refers to various types of power-driven metal cutting machines (Moltrecht 1981) such as milling, lathe and drilling machines. The facilities where machining processes are carried out are called machine shops and the individuals who operate machine tools are machinists.

The job of a machinist is to make metal parts according to a blueprint and specification. A conventional, or manual, machine tool requires a highly skilled machinist to operate it. The machinist must be able to read and interpret technical drawings, determine the appropriate machining processes and parameters, set up tools, select appropriate fixtures, manually operate the machine to cut metals into desired shapes, and inspect the dimensions and quality of the finished product using appropriate gauges and equipment.

In factories that manufacture metal products on a mass scale, the use of automation technology is important for keeping productivity and efficiency at high levels. Inevitably, the use of technology influences the division of labor and the skills required for the work. For example, the use of computer numerical control (CNC) machine tools reduces the requirement for certain skills. CNC machine tool operators have lower skill requirement than conventional machinists (Lynch, 1997). With CNC technology, the machining work is performed automatically following predetermined programs stored inside the machine. These programs are written by programmers and can be modified and used multiple times, thus saving time and effort.

The use of CNC machines in production lines allows management to divide labor into narrower specializations, such as programmers and machine operators (Hungwe 2012). Further specialization can be made at the machine operator level by dividing the role into, for example, part handler, part inspector, and machine keeper. This results in each position having a narrower work scope and skill requirement. Thus, within the context of this study, it is more accurate to refer to workers holding these job titles as 'machining workers' rather than 'machinists' to reflect their roles and relatively lower proficiency compared to a true machinist.

Dividing complex machining tasks into simpler subtasks allows a reduction in the need for 
skilled machinists on production lines. This affects hiring policy, because lower skill requirements for entry-level position means that companies do not need to hire people with machining certificates from vocational education and training (VET) institutions. Instead, companies can hire anyone as long as the person has sufficient levels of literacy and numeracy. Inevitably, when individuals with no relevant qualifications are hired, the enterprises that employ them have to provide extensive training on work-related tasks. To better understand this phenomenon, we studied the approach used by a machine shop at a car engine factory to train machining workers who began work with no formal education or training in machining-related trades; they had only secondary-level education.

\subsection{Learning at Work}

There are differing opinions on how people learn in the workplace. Marsick and Watkins (1990) described learning as incidental or a by-product of working, but not the main objective of it. Learning in the workplace is supposedly unstructured, experimental, non-institutional and integrated in the daily routines at work (Marsick and Volpe 1999). According to Eraut (2004), people who learn at work are usually unaware of their own learning because the process occurs informally. Despite the idea that learning at work is mostly informal and unstructured, there is evidence that a systematic approach is useful, especially for work that involves technical tasks. For example, the use of structured on-the-job training approaches were reported to give encouraging results for technical workers in various industries such as oil and gas (Jacobs and Bu-Rahmah 2012), aviation (Walter 2000), and manufacturing (DeJong 1993).

Billett (2013) argued against describing learning in the workplace using terms such as 'informal' or 'non-formal' because they give restrictive and negative labels to workplace learning. According to Billett, the use of such terms implies a preference for more 'formal' settings (i.e. educational institutions) and may lead to less favourable judgements against the worth of workplaces as learning environments. Billett also dismissed the idea that workplace learning lacks structure and organization. He emphasized the need to understand workplace norms and practices, as these provide the real structure to support learning experiences at work.

To promote the legitimacy of the workplace as a setting for learning, Billett (2013) stressed the need for "a theory or even a science of learning through practice" (p. 142). Billett proposed a framework for informing learning through practice. This framework has four key elements: purpose, curriculum, pedagogic practices, and personal epistemologies. This paper focused on two of these elements, namely curriculum and pedagogic practices.

Curriculum in Billett's framework is a practice-based curriculum with which learners engage in the process of learning in the workplace. Billett (2006) conceptualized the term 'workplace curriculum' as a pathway for progressing from novices to effective participants in a workplace environment. Novices start by doing simple tasks; as proficiency improves, they progress to more complicated tasks. This concept is similar to legitimate peripheral participation (Lave and Wenger 1991), where an individual gradually progresses from peripheral participation to full participation in a community of practice. 
Billett noted that this conception of curriculum is closer to the original Latin term for curriculum, i.e. currere, meaning 'the track to be run'. There is a sequence of activities that novice workers "need to engage with and progress along, which are supportive of learning processes and outcomes" (Billett, 2013, p. 147). The sequencing of activities to be learned is usually consistent with the division of labor and individuals' hierarchy at the workplace (see, for example, Marchand (2008) and Singleton (1989)).

Pedagogic practices are important factors in determining the outcome of workplace learning (Virtanen, Tynjälä, and Eteläpelto, 2014). Pedagogic practices enrich the learning experience for individuals in ways for which workplace participation by itself is inadequate (Billett 2013). In the workplace, there is hard-to-learn knowledge that will not be learned by observing or imitating others but that requires intervention and the use of learning strategies to assist learning (Billett 2011).

\subsection{Research Questions}

The main question in this study was how the machine shop provides training to machining workers who have no formal education or previous experience in machining. This was divided into two research questions. First, how did the workplace curriculum help individuals to progress from novice workers to knowledgeable workers at the machine shop? Second, what strategies were used by the machine shop to enhance the learning experiences of the machining workers? The first question relates to the concept of workplace curriculum, while the second relates to the concept of pedagogic practices.

\section{Method}

The design of this research was a qualitative case study. For this paper, the scope of our investigation on the workplace curriculum was limited to the intended curriculum. This refers to what the workplace intends or plans for the workers, which is different from the actual learning experiences that are afforded by the workplace (the enacted curriculum), or "what learners experience, construe, and learn" (Billett 2006, p. 32), or the experienced curriculum.

In our investigation on strategies to enhance learning experiences, we focused only on the strategies that were reported by managers and workplace trainers. We recognize that there may be other strategies used by supervisors and co-workers, or perhaps the workers themselves, to enhance the learning experience. However, these are beyond the scope of this paper.

\subsection{Site of the Study}

The site of this study was a machine shop at a factory that produces car engines. This engine factory is in a large automotive manufacturing facility owned by an automotive manufacturing company. The engines produced by the factory are made solely for the cars assembled at the manufacturing facility. The factory has three sections: casting, machining, and engine assembly. The raw casts produced by the casting section are machined at the machine shop. From the machine shop, the engine components are sent to the engine assembly section to be put together. Completed engines are then transferred to the car 
assembly line and fitted into vehicles.

The 'bounded system' for this study was the machine shop of the factory. This shop has 150 employees working in two shifts daily. Work is organized according to production lines where specific engine parts are made. There are nine production lines producing various parts for engines. At the machine shop, there are two learning centers with dedicated trainers: one for basic machining skills and one for $4 \mathrm{~S}$ or good housekeeping practices.

\subsection{Data Collection}

The data for this study were collected through interviews, documents, and observations. Altogether, four people were interviewed: a manager in charge of operations at the engine factory, and three workplace trainers (TR1, TR2, and TR3) who are based at the machine shop. TR1 and TR2 are both responsible for basic machining skills training, while TR3 is responsible for training on $4 \mathrm{~S}$ or good housekeeping practices. All four individuals have a formal educational background in machining. The manager, TR2, and TR3 have certificates in machining-related programs from local skills training institutions. TR1 studied machining at a secondary vocational school and graduated with a diploma in mechanical manufacturing engineering from a local polytechnic. In addition, the manager has a diploma in manufacturing management from a local college.

The interviews were semi-structured. Some queries pertaining to the research questions were set in advance before the interviews. However, during each interview, more questions were asked to clarify, or to elaborate on some of the interviewees' responses. The interviews were recorded using a digital voice recorder and then transcribed for the purpose of analysis.

Documents obtained from the company formed an important part of this study. They provided the researchers with information on how the company plans and implements learning programs at work. The documents are management presentation slides on learning center initiatives, a list of training modules for workers at the machine shop, the annual training calendar, the training schedule, the manpower arrangement plan, a man-machine chart, a sample layout of a production line, a guideline for training evaluation, an example of a skill chart sheet, and a list of workers at the machine shop, including titles and their workstations.

In addition, the first researcher was given a guided tour of the car manufacturing facility that included the engine factory, the car assembly factory, the main training department, and the training department in the machine shop. The researcher took notes and recorded observations that were later used for data analysis.

\subsection{Data Analysis}

Two strategies were used for data analysis. The first was to rely on the original research questions as a guide for examining the data; the second was to develop a case description based on a descriptive framework (Yin 2014). The descriptive framework for data analysis contains the following elements: (1) an overview of the machine shop, (2) the workplace curriculum, and (3) strategies to enhance learning experiences.

An overview is presented in the findings section to give the reader a general idea of the 
machine shop and a historical perspective of the efforts to provide a systematic approach to skill formation at the machine shop. As for the workplace curriculum, the evidence for the existence of such a curriculum was obtained from company documents and from the interviews with the manager and the trainers. To determine the strategies used to enhance learning experiences, we first conducted an inductive analysis of the interview transcripts, and then compared this with evidence from documents obtained from the factory.

\section{Findings}

The findings from the case study are reported here. First, an overview of the machine shop is presented, and second, the workplace curriculum is described. Third, the strategies used by the machine shop to enhance learning experiences are elaborated. Quotations from interview transcripts are used to support the findings. The notations used in the quotations are listed in Table 1.

Table 1: Notations used in used in quotations from transcripts

\begin{tabular}{ll}
\hline Notations & Meaning \\
\hline$\ldots$ & Significant pause \\
{$[\quad]$} & Material omitted \\
[to learn] & Explanatory material added by researchers \\
\hline
\end{tabular}

\subsection{An Overview of the Machine Shop}

The machine shop began operating in 1995. The manager said that during the early years, the shop had many workers with formal educational backgrounds in machining. During that period, workers with vocational qualifications received higher starting salaries than those with only a secondary-school qualification. For non-supervisory positions, there were six salary tiers: $1 \mathrm{~A}, 1 \mathrm{~B}, 1 \mathrm{C}, 2 \mathrm{~A}, 2 \mathrm{~B}$, and $2 \mathrm{C}$. An individual with a vocational certificate in machining-related trade would start at grade $2 \mathrm{~A}$ and would have the job title 'machinist'.

Trainers TR2 and TR3 both joined the machine shop in 2001 as machinists. Both had certificates in industrial mechanics, albeit from different VET institutions. The company gave them the title 'machinist' and a starting salary at grade 2A. TR2 explained that as a machinist, he had the starting salary grade equivalent to that of a team leader, but without the responsibility of a team leader. The main job function of machinists was to check and maintain product quality, while the main job function of team leaders was to manage production lines.

In 2003, the company's human resource (HR) department standardized the entry-level title and salary. This meant that new workers were given the same job title and starting salary, at grade 1A, regardless of qualifications. From a business perspective, the hiring policy made sense because the company could reduce costs by paying lower salaries. From an operational perspective, the policy did not cause too many problems because the machine shop had reach a period of stability. The manager explained that, unlike in niche production, where products 
change frequently, the machine shop had been doing mass production with small product variations. Major changes happened only when a new product was introduced or a new production line added. This meant that hiring highly trained workers, though desirable, was not as critical as during the early years of the machine shop. As the manager explained: "initially we want people with knowledge. Then, these people would transfer their knowledge [to other workers]."

The manager himself was a vocational graduate, having trained as a general mechanic at a VET institution in the mid-1980s. During the early part of his career, he worked on a car assembly line and later in the machine shop at an automotive company. He joined his current employer in 1995 as a supervisor in the machine shop and gained a series of promotions until he reached his current position. During the interview, he indicated his preference for having people with machining qualifications, but at the same time, said that he understood the company HR rationale for standardizing the entry-level title and pay. However, according to the manager, the effect of the hiring policy is that it has become more difficult to recruit people with vocational qualifications because they can earn higher salaries elsewhere. Although the machine shop is still able to hire workers with relevant qualifications, the turnover among them is high. These workers used their experience at the machine shop as a stepping stone to obtain better jobs elsewhere. In contrast, according to the manager, turnover among workers with secondary-school qualifications is low.

Generally, workers with only secondary-school qualifications had difficulties during the early periods of their career. TR3 commented that, "without a vocational [education] background, they may have never seen a vernier caliper, they are a little slow [to learn]". However, all the trainers agreed that the difficulties were temporary. Eventually, with training and experience, most workers improved. When comparing the difference between secondary-school graduates and vocational graduates, TR1 said that, "there are differences, but sometimes the difference is temporary. I always believe that what you know is not important. What is important is how fast you learn."

At the machine shop, CNC machines are used extensively throughout the production lines. This means that machining processes are highly automated. Workers do not do the actual cutting work, which is done by the CNC machines, but they must "control the dimensions", as emphasized by TR3. To do this, they must inspect the machined parts thoroughly, at specified intervals, and take preventive measures, such as replacing the cutting tools inside the machine, before the tolerance limit is exceeded. TR1 estimated that "70 percent of the work we do is inspection". Thus, the critical skill for working at the machine shop is the ability to use appropriate tools and gauges for product inspection and measurement. As explained by TR1, inspection is very important for product quality at the factory:

We build quality not through inspection. We build quality through process. Meaning, no matter how you check, the quality doesn't change. Quality is built during process, but inspection is our barrier for stopping [faulty] things from passing through. Rejects, defects in the factory are our problem. We don't want them to get to others.

One of the biggest challenges when hiring secondary-school graduates relates to the teaching 
of the skills they need for work. This is partly due to what the manager perceived as a "lack of teachers" at the company. As the number of new untrained workers increases, the burden of teaching them also increases. The company now has learning centers and dedicated trainers to give basic skill training to new workers, though this was not always the case. Previously, the responsibility for training junior workers mostly lay with senior workers, especially the team leaders. According to TR2, who was once himself a team leader, a team leader is like "an icon to operators". He said that, "if the team leader doesn't teach anything to an operator, then the operator will never have interest. The team leader must always think of the best ways to teach."

Technology plays an important role in expediting workers' ability to participate as productive members in the workplace. The clearest example is the use of CNC machines in production lines. A person with no experience can still work almost immediately on a production line carrying out the simplest of tasks, i.e. loading and unloading parts into the CNC machine. This task has a low skill requirement: almost everyone can do it. Another example is the use of digital calipers for measuring. They help workers to be more productive and reduce the potential for error. With technology, workers can be taught procedures for performing specific work tasks, and they may perform these tasks well without knowing the fundamentals behind them. However, technology can go wrong, and when this happens, workers with weaker knowledge of the fundamentals may find it difficult to cope. The manager gave an example of a worker who had joined the company with a secondary-school qualification and worked with a coordinate measuring machine (CMM) in the quality control (QC) department.

At QC, when he first started, we immediately taught him [to use the] CMM, coordinate measuring machine. But when the thing broke down, he couldn't go back to basics. He couldn't do it manually. So we had to come down and teach him.

In 2012, the company started to establish learning centers. The manager expressed the belief that this was the company's acknowledgement of the need to go 'back to basics'. A learning center is called a dojo. In a presentation slide prepared by the management, there was a message from the company directors explaining that one of the purposes of the dojo is to develop company workers "to be more disciplined, to acquire the necessary fundamental skills that enable them to follow SOP [standard operating procedure] to ensure that vehicles are produced at the highest quality". The presentation slide explained that the learning centers would help to relieve some of the team leaders' teaching burden, especially concerning basic skills.

The main dojo, or the dojo center, is located at a building separated from the production area. This is where the Dojo Development and Education (DDE) department is located. Under the DDE, there are satellite dojos that are given the responsibility for providing workers with basic skills training. TR1 and TR2 run the machine shop dojo at the engine factory. There are satellite dojos at other locations within the automotive manufacturing complex, for example at the press shop, body shop, paint shop, and assembly line. TR3 runs a $4 \mathrm{~S}$ dojo; however, this dojo is directly under the machine shop and not under the DDE.

TR3 explained that the term ' $4 \mathrm{~S}$ ' is derived from the first four verbs in $5 \mathrm{~S}$ - sort, straighten, 
shine, standardize; the last verb (sustain) is omitted. According to TR3, sustainability results from practicing the first four elements, hence the rationale for focusing on $4 \mathrm{~S}$ only. It is interesting to note that even though this factory, like most factories, puts great emphasis on productivity and quality, there is a conscious effort to train workers in cleanliness and good housekeeping. TR3 said:

When we keep pushing for quantity and quality, sometimes we forget about cleanliness. Perhaps there is coolant leaking on the floor and they ignore it. Because in their head, their mindset is "I want to produce output". But when the floor is slippery, it may cause injury. [ ] The training here [at the $4 \mathrm{~S}$ dojo] gives importance to taking care of the workplace. If the floor is dirty, clean it. [ ] We don't want to only produce quantity and quality but neglect other elements.

\subsection{A Workplace Curriculum for Machining Workers}

Skill formation is designed as a gradual process for machining workers at the factory. As their proficiency improves, they may progress along a designated pathway from machine operator to team leader. This serves as both a career track and a learning track (or a workplace curriculum) for workers in the machine shop. The curriculum reflects the division of labor in the machine shop. Within each production line there is a team leader with several team members in the following categories: operator, quality gate inspector, linekeeper, and spareman.

An operator is the lowest-ranked team member. This is the entry-level position for individuals who join the machine shop without formal education in machining. Operators are responsible for part handling. Their job is mainly to load parts into the CNC machines and remove them after the machining process is completed. There are two or three operators on each line. All are responsible for their own stations, which consist of a number of machines. Operators walk from machine to machine, loading and unloading parts into each one. They may also have to do additional manual tasks at each machine, as well as some cleaning work.

Once operators are proficient in their current station, they can be transferred to another station, and may subsequently be considered for promotion to quality gate (QG) inspector. The role of a QG inspector is to inspect every part that comes out of every single machining process within a production line. According to TR1, the type of inspection work performed by QG inspectors is not too detailed. Their work mostly involves visual inspection, tactile inspection for surface roughness, and some inspection using gauges.

After the QG inspector, the next progression is to be a linekeeper. A linekeeper also performs inspection duties, but by sampling (for example, 1 in every 20 parts), rather than inspecting every part, as a QG inspector does. Linekeepers inspect parts to determine whether the precision is within an acceptable range. They use this information to determine, for example, when the tools inside the CNC machines must be changed in order to keep the part tolerance within acceptable limits. Linekeepers also carry out machine inspection and troubleshooting when machines break down.

After the linekeeper, the next progression is to be a spareman. The job title is a little 
misleading. Sparemen are the workers who take over the role of absent team members. However, this is not their main duty. When not replacing other workers, they have more important duties pertaining to line management, including reporting, data updating, machine problem countermeasures involving parameter control, and total productive maintenance. TR1 described a spareman as a "multi-skilled" worker. The spareman assists the team leader in managing the line, but at the same time doubles as a backup for an absent team member.

Finally, a spareman can be promoted to team leader when ready, and of course, when there is a vacancy for the job. The trainers interviewed agreed that to be a team leader a person needs additional characteristics beyond the knowledge, skills, and attitude required for ordinary machining workers. TR3 said that a person considered for the team leader position must be "able to teach and to influence people". TR1 said that this person needed "added values" such as proactiveness, operational skills, and management skills. The differences between the title holders and their main scope of work are compared in Table 2.

Table 2: Title and main scope of work

\begin{tabular}{ll}
\hline Role & Main scope of work \\
\hline Operator & Part handling, chip cleaning \\
QG inspector & Final inspection for each part \\
Linekeeper & Quality check, tool change, machine inspection and troubleshooting \\
Spareman & Line arrangement, machine problem countermeasure \\
Team leader & Manpower arrangement, cross-check team member activities \\
\hline
\end{tabular}

\subsection{Strategies to Enhance Learning Experiences for Machining Workers}

Providing training at work for machining workers who have no formal education or previous experience in machining is not an easy task. The technicalities of the subject matter may cause difficulties for inexperienced workers, especially when they have had no prior exposure to the field of machining technology. Several strategies had been used in the machine shop to enhance the learning experience for workers: (1) ensure sufficient mathematical skill, (2) use syllabus and training modules, (3) maximize opportunities for practice, and (4) continuously assess skill proficiency. The descriptions of these strategies are explained here.

\subsubsection{Ensure Sufficient Mathematical Skill}

When hiring individuals with only secondary-school qualifications, the machine shop requires people with a reasonably good grade in mathematics. A fail or low pass in mathematics is not acceptable, although failures in other subjects are tolerated. The manager explained the rationale for this requirement based on his experience in dealing with workers who had failed mathematics:

I've hired someone who failed maths. When we want to give him work, he was difficult to teach. As if he couldn't adapt. Had to explain four or five times before he understood. If the maths is okay, but BM [Bahasa Melayu, or Malay language] failed, never mind. He can be 
fast.

Mathematical skill is important for machining workers because a large part of their work on production lines involves measuring. The dimensions of a particular part are usually stated within a certain limit of tolerance (for example, the diameter of a finished part has to be 50 $\mathrm{mm} \pm 0.005 \mathrm{~mm}$ ). From the manager's own experience, someone who failed mathematics may confuse plus and minus in a measurement unit. Furthermore, there are certain concepts, such as part geometry, that a person who lacks mathematical skill may find difficult to grasp. TR1 explained that:

Measurement is first [number one in priority]. Because measurement is the guarantee of quality. [ ] For all work we do, we must check. If we do our work correctly, but check it wrongly, that is considered wrong. But if we work wrongly, check correctly, that is still acceptable [ ] Measurement in machining is not simply just in length or diameter [ ] we have geometric characteristic, the shape of the thing. If he can understand that, then other things will be easy. Then we can talk about cutting tools, coolant, machine and other things.

Even though the manager requires someone with a good grade in mathematics, new workers are still tested to assess their mathematical skills. In addition, new workers are tested on their ability to measure using just a simple ruler. According to TR1:

Before we train them, we need to know their level [ ] For a new guy, first, we give him a mathematics test. See if his math is ok, then we can forget about it [ ] Next is measurement. Give [him] an item, give a ruler, read the ruler [measure the item], if he can read the ruler, then we go next to micrometer, vernier caliper. If he can't, we may have to start with mathematics.

\subsubsection{Use Syllabus and Training Modules}

The machine shop modularizes training to achieve more systematic lesson delivery. Modularizing means dividing the learning content into distinct units based on topics to create training modules. Trainers at the machine shop dojo are responsible for delivering the training modules to workers. There are currently 36 training modules at the machine shop. Our analysis of the machining training plan indicates that the highest number of modules (27 modules) is in the skills category. Other categories have far fewer modules: for example, the morale category has two modules, the general knowledge category four modules, and the management category one module. There is also a 'module level-up' category that contains added-value modules to further develop workers' expertise.

Modules in the skills category are essentially the training syllabus for machining workers in various positions. The skill category has four subcategories: (1) basic measurement, judgement, and setting, (2) inspection gauges, (3) tool changing, and (4) tool presetting. Modules in the first subcategory cover the basic skills: the use of touch to assess surface roughness, and proper techniques for using the vernier caliper, micrometer, and t-hex wrench. This is the basic syllabus for an operator to be trained to become a QG inspector. The subsequent skill subcategories cover the basic training syllabus for a QG inspector to upgrade to a linekeeper. In the second subcategory for skill (inspection gauges), there are 11 modules; 
all of them relate to the use of gauges used for inspecting parts on the production line. In the third subcategory (tool change), there are seven modules that relate to the techniques for replacing various types of tools, such as drills, inserts, milling cutters, and boring bars. In the fourth subcategory (tool presetting), there are five modules that relate to the techniques for presetting various tools, such as tap, drill, and reamer. A list training module category is shown in Table 3.

Table 3. Training module categories, modules, and content

\begin{tabular}{lll}
$\begin{array}{l}\text { Training } \\
\text { category }\end{array}$ & $\begin{array}{l}\text { No. of } \\
\text { modules }\end{array}$ & Module content \\
\hline $\begin{array}{l}\text { Morale } \\
\text { General knowledge }\end{array}$ & 4 & $\begin{array}{l}\text { Basic rules and morale, quality dojo } \\
\text { Safety, quality, engine mechanism, Kanban }\end{array}$ \\
$\begin{array}{l}\text { Skills } \\
\begin{array}{l}\text { Basic measurement, } \\
\text { judgement \& setting }\end{array}\end{array}$ & 4 & Surface roughness, caliper, micrometer, t-hex wrench \\
$\begin{array}{l}\text { Inspection gauges } \\
\text { Tool change }\end{array}$ & 11 & Measurement using 11 different type of gauge \\
Tool presetting & 5 & Replacement of various types of tool \\
Management & 1 & Technique for presetting tools \\
Module level-up & 2 & Production line management \\
\hline
\end{tabular}

According to TR1, the training modules are not intended for new employees. New workers have to spend time working on the production lines before attending training at the machine shop dojo. They must first work as operators, doing part handling on the production line. This work has a low skill requirement, and hence, on-the-job instruction is sufficient. But this initial assignment gives new workers a true experience of what is it like to work on a production line. According to TR2, someone who shows a lack of interest in this experience will quit the job fairly soon.

\subsubsection{Maximize opportunities for practice}

Another strategy for enhancing the learning experience for workers is to maximize the opportunities to practice what was taught during training. This is done in several ways. First, according to TR1, there must be "a balance between knowledge and practice". The trainers tried not to teach too many things at once; instead, they allowed sufficient time for workers to practice what had been taught. Previously, a training session lasted for about a week. The trainers found that workers had difficulty retaining knowledge when so many things were taught at once. According to TR1:

We taught many topics - topics we thought were very basic. After a year, we checked [and realized that] many operators couldn't remember everything that was taught [ ] we taught 
many things, but they couldn't remember them and they couldn't practice them.

The current approach is to have training of shorter duration and allow time for workers to practice what was taught before the trainers begin a new training session. According to TR1:

We teach a little, we don't teach for long. One day, or two days only, then we release them to the [production] line. Let them practice. Then we audit whether they did it correctly or not.

The number of participants in each training session is small - a maximum of five workers. Part of the reason for this is the demands of production: not many workers can be released for training at any one time. However, the small number of participants makes it easier for the trainers to give personal training or personal coaching to workers. The important thing, according to TR1, is for workers "to understand what was taught".

At the machine shop, workers were initially taught the skills that they needed without too much emphasis being given to the theories behind them. This is the opposite of what normally happens in school, where theoretical lessons precede practical lessons. The advantage of this approach is that it expedites the skill-acquisition process and prevents workers from losing interest in the theoretical knowledge.

\subsubsection{Continuously Assess Skill Proficiency}

Assessment is important for determining whether workers have successfully mastered the skills that they were taught. Workers who attend training are assessed by the trainers. According to TR2, if workers do not pass a particular test, they may have to repeat the training. The machine shop uses a skill chart as an indicator of workers' skill. Every worker has a skill chart. Superiors are responsible for assessing the skills of their subordinates; for example, team leaders will assess team members, and supervisors will assess team leaders. This assessment is done quarterly. The trainers will report to team leaders on the training performance of their team members.

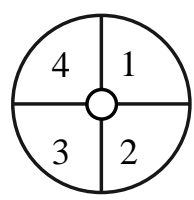

A

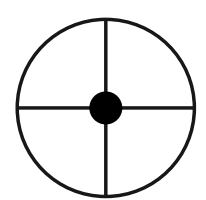

B

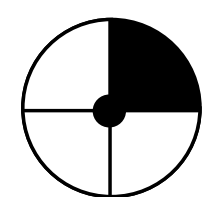

$\mathrm{C}$

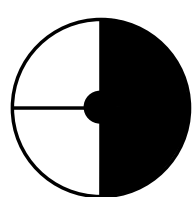

$\mathrm{D}$

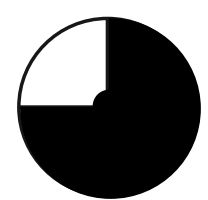

$\mathrm{E}$

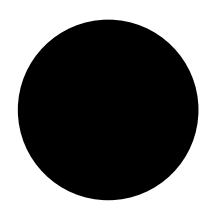

$\mathrm{F}$

Legend: A - No target process, B - Has target process, C - Possesses basic skills, requires supervision, needs training, D - Can work under minimum supervision, needs training, E Knowledgeable / competent, needs training (if available), F - Knowledgeable / competent, can teach others, no training required

Figure.1 Skill charts for machining workers

An example of a skill chart is shown in Figure 1. It has four quadrants: the first is for those who have minimal skills and need supervision and training; the second is for those who have skills and are able to work with minimum supervision but still need training; the third is for those who can do their job well and would benefit from some training if available; and the 
fourth is for those who can do their jobs well and can teach other workers. The small circle in the middle of the chart indicates whether a worker has a particular process target (or job scope) relevant for a particular skill subcategory.

Figure 1 is based on a sample skill chart sheet for machining workers on one of the production lines. The sheet has a list of team members and the team leader in rows, and the skill charts in columns. There are five skill charts for each person. They match all four subcategories of the skills category (refer Table 3) namely: (1) basic measurement, judgement, and setting, (2) inspection, (3) tool change, and (4) tool presetting, and an additional chart for machine operation.

A competent QG inspector, for example, may have an impressive skill chart for the subcategory of basic measurement, judgement, and setting (similar to item F in Figure 1), but the skill chart for other subcategories such as tool change and tool presetting may be less impressive because these subcategories are not relevant to the inspector's current scope of work. At the machine shop, skill charts play an important role when machining workers are being considered for promotion along the progression pathway.

\section{Discussion}

This study looked at skill formation at work from the perspective of an employer. The machine shop selected for this study is a fair representation of employers in the Malaysian manufacturing industry, where a large majority of the workforce is educated to secondary level.

As stated previously, the main question was how the machine shop provides training to machining workers who have no formal education or previous experience in machining. There were two research questions. The first was related to the concept of workplace curriculum (Billett 2006): how did the workplace curriculum help individuals to progress from novice workers to knowledgeable workers at the machine shop? Findings from the study indicate the existence of a workplace curriculum in the form of a gradual progression pathway for machining workers. From an entry-level position as an operator, a worker can progress to become a quality inspector, linekeeper, spareman, and team leader.

Each level of progression is an exact reflection of how labor is divided at the machine shop. However, the progression levels are not a true reflection of the hierarchy. Everyone on a production line, except the team leader, has the same rank. They are all team members. With the exception of promotion from spareman to team leader, progress along the pathway is not so much a progression of rank as a progression of knowledge and skills.

The second research question was related to the concept of workplace pedagogy: what strategies were used to enhance the learning experiences of machining workers? Findings from the study identified the strategies used to minimize the impact of workers having a lack of education in machining. For example, by ensuring that workers have sufficient mathematical skills, the machine shop tries to enhance the opportunities for workers to successfully comprehend technical concepts and knowledge associated with machining technology. Another strategy is to maximize opportunities for practice, which seems to reflect 
the machine shop's emphasis on giving machining workers plenty of opportunities to transfer learning from a training situation to an actual work situation.

Other strategies seem to be designed to ensure that the hard-to-learn knowledge can be learned systematically. For example, the use of a syllabus and training modules helps trainers and workers to identify the skills needed to progress from one job category to another. Another strategy, the continuous assessment of skills, helps trainers, team leaders, and supervisors to identify those workers who are making good progress and who can be considered for promotion.

This case study showed how an employer overcome the problem of not having skilled machinists by recruiting secondary-school graduates and providing them learning opportunities. Advanced skill in machining technology is not needed for an entry-level position in an automated mass-production environment. The utilization of technology (CNC machines) in such an environment is a major factor that reduces the need for highly skilled machinists. Furthermore, the fact that the factory is designed for mass production, with high volumes and small product variations, leads to relative stability and also reduces the need to have many highly skilled machinists.

Company-based training is one of the ways in which school leavers can obtain initial training (Atkinson 1999). The advantage of this form of training is its ability to deliver highly relevant job-specific skills training (Korpi, de Graaf, Hendrickx, and Layte, 2003). The opposite of this approach is school-based or institution-based initial training, which is the most dominant form of vocational training in Malaysia. Currently, there are many VET institutions in the country that offer programs for machining education and training, but these are designed to produce machining and manufacturing technicians rather than entry-level machining workers. Graduates from these programs are likely to demand technician-level salaries. They may not be suitable for entry-level jobs at machine shops similar to the one described in this study.

In this study, workplace-based training was the suitable method for training new workers. The low skill requirements for entry-level positions means that the machine shop can hire secondary-school graduates to work on production lines. The division of labor on the production lines allows for gradual progression from novice worker to knowledgeable worker. This case study provides an example of how the concept of workplace curriculum (Billett, 2006; 2011) is applied within an industrial setting. The findings from this study support the existence of a workplace curriculum as conceptualized by Billett: a pathway to be followed for acquiring work knowledge and skills.

\section{Conclusion and Recommendation}

This study has shown that workplace-based training is a feasible approach for training people who lack formal education in a particular field of work. It demonstrates that learning at work is not necessarily informal or unstructured. There is a structure, or a workplace curriculum, that a learner needs to go through in order to progress from a novice worker to a knowledgeable worker. The study also shows how the workplace can play an active role in helping individuals to learn at work. However, this study only observed the perspectives of 
management and trainers on workplace training for workers. Further studies from the workers' perspective are also needed to create a complete picture of learning at work. Another area for further study could be the potential of workplace-based training to complement the existing VET system in relation to machining. Workplace-based training is an attractive proposition because, unlike institution-based vocational training, it is largely funded by the private sector, and thus does not require financial support from the government.

\section{Acknowledgement}

This study was supported by Universiti Putra Malaysia research grant (Geran Putra - Inisiatif Putra Siswazah), project number 9394200.

\section{References}

Atkinson, D. (1999). The financing of vocational education and training in the United Kingdom: financing portrait. Thessaloniki, Greece: CEDEFOP.

Billett, S. (2006). Constituting the workplace curriculum. Journal of Curriculum Studies, 38(1), 31-48.

Billett, S. (2011). Workplace curriculum: practice and propositions. In F. Dochy, D. Gijbels, M. Segers, and P. Van Den Bossche (Eds), Theories of workplace learning: building blocks for training and professional development programs (pp. 17-36). London: Routledge.

Billett, S. (2013). Learning through practice: beyond informal and towards a framework for learning through practice. In K. Ananiadou (Ed.), Revisiting global trends in TVET: reflections on theory and practice (pp. 123-163). Bonn, Germany: UNESCO-UNEVOC.

DeJong, J.A. (1993). Structured on-the-job training at Hoogovens IJmuiden. Journal of European Industrial Training, 17(2), 8-13.

Department of Statistics (2012). Report on the survey of manufacturing industries. Putrajaya, Malaysia: Department of Statistics.

Department of Statistics (2013). Labour force survey report: Malaysia, 2013. Putrajaya, Malaysia: Department of Statistics.

Eraut, M. (2004). Informal learning in the workplace. Studies in Continuing Education, 26(2), 247-273.

Hungwe, K. (2012). Identity, self-interpretation and workplace change: an investigation of the work activity of machining. Journal of Adult Development, 19(3), 123-140.

Jacobs, R.L., \& Bu-Rahmah, M.J. (2012). Developing employee expertise through structured on-the-job training (S-OJT): an introduction to this training approach and the KNPC experience. Industrial and Commercial Training, 44(2), 75-84.

Korpi, T., de Graaf, P., Hendrickx, J., \& Layte, R. (2003). Vocational training and career employment precariousness in Great Britain, the Netherlands and Sweden. Acta Sociologica, 


\section{Macrothink \\ International Journal of Learning and Development \\ ISSN 2164-4063 \\ 2016, Vol. 6, No. 4}

46(1), 17-30.

Lave, J., \& Wenger, E. (1991). Situated learning. Legitimate peripheral participation. Cambridge: Cambridge University Press.

Lynch, M. (1997, April 1). Key CNC concept \#1 - the fundamentals of CNC. Modern Machine Shop. Retrieved May 19, 2015 from http://www.mmsonline.com/articles/ key-cnc-concept-1 the-fundamentals-of-cnc

Marchand, T.H.J. (2008). Muscles, morals and mind: craft apprenticeship and the formation of a person. British Journal of Educational Studies, 56(3), 245-271.

Marsick, V., \& Watkins, K.E. (1990). Informal and incidental learning in the workplace. London: Routledge.

Marsick, V., \& Volpe, M. (1999). The nature and need for informal learning. Advances in Developing Human Resources, 1(3), 1-9.

Moltrecht, K.H. (1981). Machine shop practice (2nd ed.) New York: Industrial Press.

Singleton, J. (1989). The Japanese folkcraft pottery apprenticeship: cultural patterns of an educational institution. In M.W. Coy (Ed.), Apprenticeship: from theory to method and back again (pp. 13-30). New York: State University of New York Press.

Virtanen, A., Tynjälä, P., \& Eteläpelto, A. (2014). Factors promoting vocational students' learning at work: study on student experiences. Journal of Education and Work, 27(1), 43-70.

Walter, D. (2000). Competency-based on-the-job training for aviation maintenance and inspection - a human factors approach. International Journal of Industrial Ergonomics, 26(2), 249-259.

Yin, R.K. (2014). Case study research: design and methods (5th ed.). Thousand Oaks, CA: Sage Publications.

\section{Copyright Disclaimer}

Copyright for this article is retained by the author(s), with first publication rights granted to the journal.

This is an open-access article distributed under the terms and conditions of the Creative Commons Attribution license (http://creativecommons.org/licenses/by/3.0/). 